\title{
Integrated Chinese and western medicine interventions for atopic dermatitis: a systematic review and meta-analysis
}

\author{
Chi Him Sum ${ }^{1}$, Jessica Ching ${ }^{1,2}$, Hongwei Zhang ${ }^{1,2}$, Steven Loo², Cho Wing Lo', Mei Kwan Lai', \\ Pui Kuan Cheong ${ }^{1}$, Chau Leung Yu ${ }^{1}$ and Zhi-xiu Lin ${ }^{1,2^{*}}$ (B)
}

\begin{abstract}
Background: Atopic dermatitis (AD) is a chronic relapsing skin disease characterized by recurring episodes of itchiness with skin erythema and surface damages. Chinese medicine $(C M)$ is widely used for the management of AD in China not only by its own, but also used in combination with conventional therapy (integrated Chinese-Western medicine, ICWM). Although many clinical trials on the effectiveness of ICWM on AD have been conducted, however, up to date, no sound evidence has been established on the clinical effectiveness and safety of ICWM for AD.
\end{abstract}

Objectives: To systematically review the currently available clinical evidence on the clinical effectiveness and safety of ICWM for AD.

Methods: Randomised and quasi-randomised controlled trials, which investigated ICWM interventions with at least one control group using the same conventional interventions, no treatment or placebo treatment, were included. Four English (CENTRAL, MEDLINE, EMBASE, AMED) and three Chinese (CNKI, CBM, WanFang Med) databases were searched. Risk of bias was assessed according to the Cochrane's tool. Meta-analysis was performed to pool the data.

Results: From 1473 entries, 55 studies were included, involving 5953 participants aged between 35 days and 67 years old. Duration of treatment ranged from 1 to 24 weeks. Only 2 studies were judged to have low risk of bias, 3 studies had unclear risk of bias, and the other 50 studies were with high risk of bias. ICWM was found to be superior over WM alone in improving clinical severity of AD (measured by EASI, SCORAD), health-related quality of life (measured by CDLQI, DLQI), long term control of AD (recurrence rate), patients/investigator global score (clinical effectiveness rate), and serum IgE level. Adverse events associated with ICWM were found to be comparable with WM alone.

Conclusion: ICWM seems to produce superior treatment response than WM alone in managing AD without increased risk of adverse events. However, the current available evidence remains too weak to make a conclusive decision.

Keywords: Atopic dermatitis, Integrated Chinese-Western medicine, Chinese medicine, Systematic review, Metaanalysis

*Correspondence: linzx@cuhk.edu.hk

${ }^{1}$ Hong Kong Institute of Integrative Medicine, The Chinese University of Hong Kong, Shatin, N.T., Hong Kong, China

Full list of author information is available at the end of the article

\section{Background}

Atopic Dermatitis (AD) is a chronically relapsing skin disease characterized by recurring episodes of itchiness with skin erythema, dryness, thickening and swelling [1, 2]. AD skin lesions usually appear on the face, neck, back of the hands and feet, and itchiness and sleep loss are the original author(s) and the source, provide a link to the Creative Commons licence, and indicate if changes were made. The images or other third party material in this article are included in the article's Creative Commons licence, unless indicated otherwise in a credit line to the material. If material is not included in the article's Creative Commons licence and your intended use is not permitted by statutory regulation or exceeds the permitted use, you will need to obtain permission directly from the copyright holder. To view a copy of this licence, visit http://creativecommons.org/licenses/by/4.0/. The Creative Commons Public Domain Dedication waiver (http://creativeco mmons.org/publicdomain/zero/1.0/) applies to the data made available in this article, unless otherwise stated in a credit line to the data. 
most significant clinical symptoms. It affects around $15 \%$ to $30 \%$ of children and $2 \%$ to $10 \%$ of adults worldwide [3, 4]. In Hong Kong, the incidence rate of AD was $15 \%$ to $20 \%$ of the general population [5].

The pathogenesis of $\mathrm{AD}$ involves interactions among genetic and environmental factors, skin barrier dysfunction, microbial imbalance and immune dysregulation [6-8]. Multiple factors are believed to underlie dysfunctional T-helper (Th) cell type 1, Th2, and Th17 innate and adaptive immune responses in patients with $\mathrm{AD}[7$, 8]. Currently anti-inflammatory treatment with topical corticosteroids and/or topical calcineurin inhibitors is widely used for the management of mild to moderate form of $\mathrm{AD}$, while systemic immunosuppressive agents, such as glucocorticoids, cyclosporine, or methotrexate, can be used in severe cases $[8,9]$. Long-term topical corticosteroid use is associated with side effects including stretch marks, small red or purple spots, telangiectasia (small, dilated blood vessels on the surface of the skin), skin thinning, atrophy and acne. Topical use of excessive corticosteroids can also cause hypothalamic-pituitary axis suppression $[1,6]$. The systemic immunosuppressive agents do not target specific points of immune dysregulation in $\mathrm{AD}$, and may result in severe adverse events, including liver and kidney impairment. Ultraviolet phototherapy can be used for generalized $\mathrm{AD}$, but it is contraindicated in children and young adults because of its long-term use is associated with the occurrence of skin cancer.

Complementary and alternative medicine has been increasingly used for the management of AD worldwide [10]. Chinese medicine (CM) is nowadays widely used for treating $\mathrm{AD}$ in East Asia and provides a valuable alternative treatment option. Many clinical studies have been conducted to evaluate the effectiveness of Chinese herbal medicines (CHMs) for the treatment of $\mathrm{AD}$ in recent decades $[11,12]$. Findings suggested that oral use of CHMs may improve health-related quality of life for children with moderate or severe atopic eczema. As integrated Chinese and Western medicine (ICWM) is a common way of clinical practice in mainland China, many clinical studies have been published on the effectiveness of ICWM on AD [13]. However, currently no solid evidence is available to support the effectiveness and safety of ICWM for AD treatment.

Since 1997, the Hong Kong Special Administrative Region Government has adopted an evidence-based approach in promoting the use of ICWM. High quality evidence on the use of ICWM is in urgent need. We would therefore like to fill in the gap by conducting a systematic review focusing on the use of ICWM for AD. The evidence synthesized would likely help develop a pragmatic collaborative care model for both WM and $\mathrm{CM}$ practitioners for the management of $\mathrm{AD}$ in Hong Kong.

\section{Methods \\ Eligibility criteria}

We included randomised controlled trials (RCTs) or quasi-RCTs using a superiority design, which evaluated the use of investigated WM \& CM interventions or its variants on the patients with atopic dermatitis. The herbal medicines included single herb, classical formulae, new formulae, herb-derived products and combination products. The control group should receive the same WM interventions, no treatment or placebo. The WM medicine included both oral and topical application of chemical drugs such as antihistamines, corticosteroids and other modalities such as UV light therapy.

Studies on "chronic eczema", "subacute eczema" and "acute eczema" were generally excluded, except when they use a recognized diagnosis of AD such as the Hanifin and Rajka's criteria or the UK working group criteria explicitly [14]. Studies on other types of eczema such as anal eczema, genital eczema, dyshidrosis, eczema rhagadiforme, keratinized eczema were all excluded. Trials with co-morbidity other than allergy-related diseases (e.g. asthma) were also excluded.

The included studies should report one or more of the following primary and secondary outcomes. The primary outcome was the clinical severity of eczema, measured by a validated or objective tool, such as eczema area and severity index (EASI), scoring atopic dermatitis (SCORAD), six area, six sign atopic dermatitis (SASSAD) severity score, investigators' global assessment (IGA), and affected body surface area (BSA). The secondary outcomes included participant-reported symptoms, health-related quality of life, long-term control of atopic dermatitis (defined as the status of disease control at least 1 week after the end of intervention, such as recurrence rate), serum IgE level and adverse events. The percentage of trial participants with more than 50\% improvement in terms of patients or investigator global score ("clinical effectiveness rate", further explained in "Results" section) was also accepted as one of secondary outcomes as it is widely used in the studies conducted in China based on national guidelines.

Participant-reported symptoms should be measured by a validated tool, such as patient-oriented eczema measure (POEM) and Pruritus Visual Analogue Scale (pruritus VAS). Health-related quality of life should also be measured by a validated measure, such as Dermatology Life Quality Index (DLQI) and Children's Dermatology Life Quality Index (CDLQI). 


\section{Search strategy}

Literature search strategies were developed using medical subject headings and text words related to eczema. Various synonyms of the concepts of "eczema", "Chinese medicine", "integrative medicine" and "randomised controlled trials" were combined by "And" to construct the searching strategies. We searched the Cochrane Central Register of Controlled Trials (CENTRAL, via Cochrane Library, searched on 16 Oct 2019), MEDLINE (via Ovid, 1948 to 16 Oct 2019), EMBASE (via Ovid, 1974 to 16 Oct 2019) and AMED (via Ovid, 1985 to 16 Oct 2019). We also searched the main Chinese databases including the China National Knowledge Infrastructure (CNKI, 1915 to 18 Oct 2019), the Chinese BioMedical Literature Database (CBM, via SinoMed, 1978 to 18 Oct 2019) and Wanfang Med Online (For dissertations and conference proceedings only, 1998 to 18 Oct 2019).

Previous systematic reviews or meta-analyses on $\mathrm{AD}$ were also examined to identify potential trials eligible to be included.

\section{Data extraction}

The systematic review was conducted and reported according to the Cochrane Handbook for Systematic Review of Interventions (version 5.1) and the Preferred Reporting Items for Systematic Reviews and MetaAnalyses (PRISMA) guidelines [15, 16].

All titles and abstract of the entries returned by the search were imported into Covidence, an online collaboration tool designed to facilitate the work in different stages in systematic reviews, to remove duplicates and enable online screening. A review author $(\mathrm{SCH})$ independently screened all the titles and abstracts against the original inclusion and exclusion criteria, and obtained full-texts of all entries that matched the inclusion criteria. Each of four reviewers $(\mathrm{SCH}, \mathrm{LMK}$, $\mathrm{LCW}, \mathrm{CPK}$ ) then screened part of the obtained full text articles and extracted characteristics of the studies. Another reviewer (LCW) rescreened the titles and abstracts classified as irrelevant to ensure completeness of inclusion, and a reviewer ( $\mathrm{SCH}$ ) rescreened the articles that did not explicitly describe atopic dermatitis (e.g. those articles that used "acute eczema", "subacute eczema" or "chronic eczema") to check whether AD's criteria were actually used for those studies. All questionable cases were referred to another reviewer (LZX) for decision. The final list of included articles was then determined. We resolved disagreement through discussion, and recorded the reasons for excluding articles/ studies. The review authors were not kept blind to the journal titles or to the study authors or institutions.
One review author $(\mathrm{SCH})$ extracted outcome data in the included studies and input them onto an excel spreadsheet. The means, standard deviations of continuous outcomes and the numbers of events of dichotomous outcomes were recorded. Other information including age, diagnosis, type of intervention (including constituent component and dose), randomisation method, sample size, primary and secondary outcome types were also recorded.

\section{Risk of bias assessment}

Two review authors ( $\mathrm{SCH}$ and $\mathrm{LCW}$ ) independently assessed potential risks of bias in all included studies using the Cochrane's tool for assessing the risk of bias [15]. They assessed all six domains (sequence generation; allocation concealment; blinding of participants, personnel, and outcome assessors; incomplete outcome data; selective outcome reporting; and other sources of bias) in each study and assigned a scale of high, low, or unclear risk of bias. The discrepancy in judgment was resolved by another author (ZHW).

\section{Data synthesis and statistical analysis}

We used risk ratio (RR) with $95 \%$ confidence intervals (CI) to summarize dichotomous outcome data of individual studies, and used Mantel-Haenszel randomeffects model to pool the results across studies. We used the mean difference (MD) with 95\% CI to summarize continuous outcome data at the end of treatment or follow-up within studies, and used the inverse-variance random-effects model to pool the results. For meta-analysis, we used random-effects model because of the expected heterogeneity of the studies. RevMan 5.1 software was used for data analyses. Forest plots were made to assess the effect size and corresponding 95\% CI using random-effects models. Heterogeneity was assessed using the $I^{2}$ test with the significance level set at $I^{2}$ over $50 \%$ or $P<0.1$.

We planned to perform subgroup analyses based on patients' age (less or more than 12); however, this was eventually found to be infeasible as the majority of included studies (31 out of 56) contained patients of both age groups. We assessed the possibility of publication bias by using funnel plots when at least 10 studies reported the outcomes. Sensitivity analyses were performed to evaluate the influence of study methodological quality and that of using change from baseline data (with missing standard deviation imputed) instead of post-intervention data, when the imputation of standard deviation could be made based on available data. 


\section{Results}

\section{Study selection}

The electronic database search returned 1473 records. A total of 998 records remained after duplicates were removed. After the title and abstract screening, 650 irrelevant records were excluded and 348 full-text records were assessed for eligibility. And 6 additional records were identified from previous systematic reviews and trial summaries. Eventually, a total of 55 trials (in 61 search records [17-77]) were included. (Fig. 1, flow of study selection).

\section{Study characteristics}

All 55 included studies were randomised controlled trials (RCTs). Among them, 5 studies were published in English and the remaining ones in Chinese. The included studies involved 5953 participants. The age of participants ranged from 35 days to 67 years old. Around 64\% of the included studies (35 out of 55, involving 2987 participants) explicitly excluded patients who had received certain western medicine treatment (systemic corticosteroids: 35 studies, 2987 participants; immunosuppressants: 19 studies, 1680 participants; topical corticosteroids: 18 studies, 1256 participants; immunomodulators: 17 studies, 1577 participants; antihistamines: 16 studies, 1273 participants; antibiotics: 9 studies, 588 participants; phototherapy: 6 studies, 479 participants) within certain period (7 days to 2 months before screening) from participating in the trials.
All the included trials compared the use of Chinese herbal medicine combined with Western medicine to the use of same Western medicine alone (baseline treatment). CHMs included oral and topical use of Chinese herbal medicine in the form of decoction, granules or proprietary Chinese medicine ( $\mathrm{pCm})$.

Western medicine treatment included oral and topical medicines (such as emollients, antihistamines, topical corticosteroids, topical calcineurin inhibitors, urea-containing cream, antibiotics, anti-septic solutions, vitamin $C$ or non-pharmacological therapy such as UV light therapy). The duration of treatment ranged from 1 to 24 weeks.

For primary outcomes, the included studies reported EASI, SCORAD, SASSAD, IGA (Clinical severity of eczema), POEM and pruritus VAS (Participant-reported symptoms). The most commonly reported (count $\geq 5$ ) primary and secondary outcomes among the selected domains were clinical effectiveness rate (49 RCTs), SCORAD (20 RCTs), recurrence rate (16 RCTs), IgE level (12 RCTs), EASI (8 RCTs), and pruritus relief in Visual Analogue Scale (5 RCTs).

\section{Chinese medicine syndromes and Chinese herbal medicines}

Twenty-seven studies mentioned some types of Chinese medicine syndrome 證候, and totally 15 syndromes were identified in those studies (Table 1). The four most common syndrome types were damp-heat 濕熱 (566

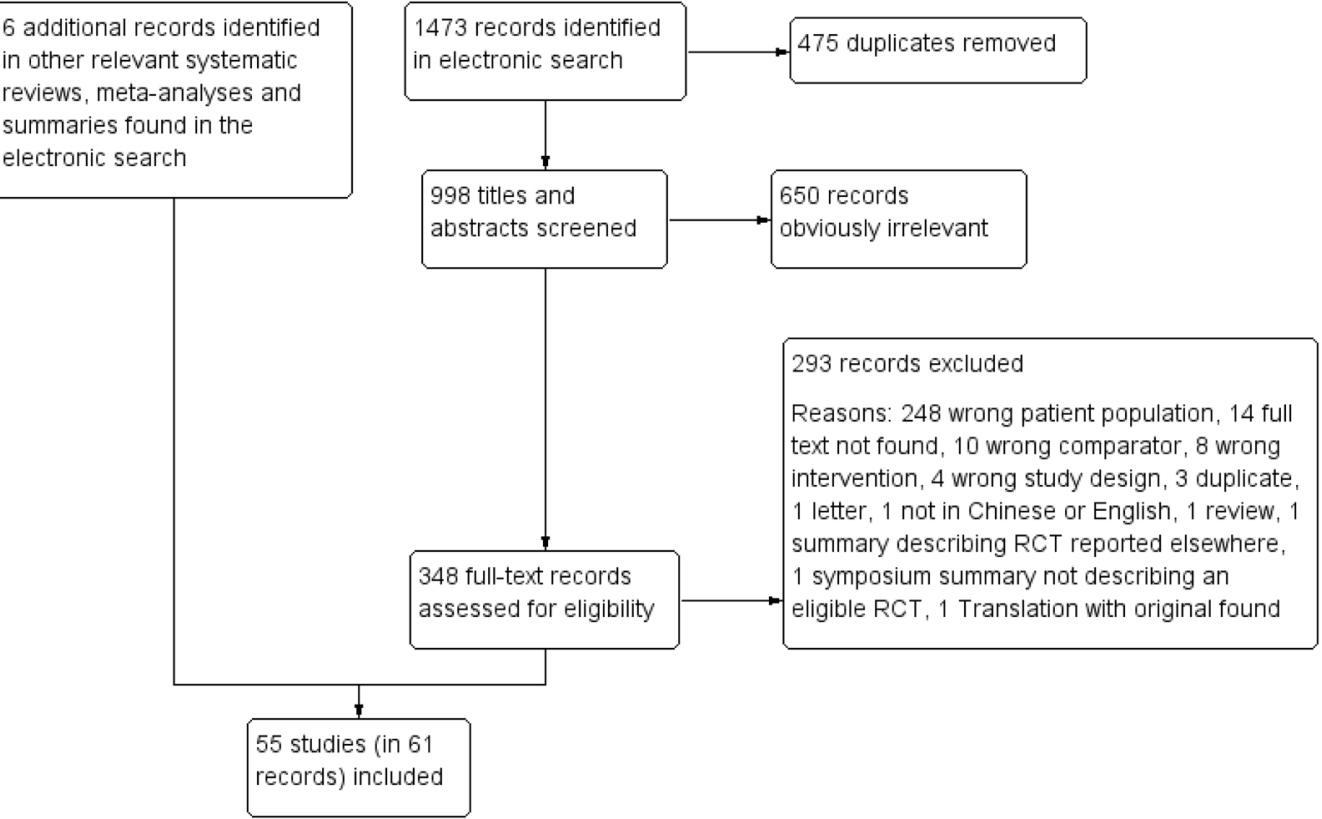

Fig. 1 Flow of study selection 
Table 1 CM syndromes identified in the included studies

\begin{tabular}{|c|c|c|}
\hline CM syndromes in Chinese & English translation & $\begin{array}{l}\text { No. of } \\
\text { participants }\end{array}$ \\
\hline 濕熱 & Damp-heat & 566 \\
\hline 脾虛濕蘊 & Spleen deficiency with dampness accumulation & 377 \\
\hline 脾虛 & Spleen deficiency & 309 \\
\hline 血虛風燥 & Blood deficiency and wind-dryness & 304 \\
\hline 風濕熱 & Wind-damp-heat & 104 \\
\hline 脾腎虛寒 & Spleen and kidney yang deficiency & 97 \\
\hline 脾虛風燥 & Spleen deficiency with wind-dryness & 90 \\
\hline 風濕蘊膚 & Wind-dampness accumulation in skin & 72 \\
\hline 心火偏盛 & Hyperactive heart fire & 60 \\
\hline 濕滯 & Dampness stagnation & 60 \\
\hline $\begin{array}{l}\text { 脾虛型伴有 } \\
\text { 陰虛症狀 }\end{array}$ & Spleen deficiency accompanied with yin deficiency & 60 \\
\hline 脾虛心火 & Spleen deficiency with heart fire & 47 \\
\hline 脾虛血燥 & Spleen deficiency with blood dryness & 47 \\
\hline 胎熱型 & Fetal heat & 40 \\
\hline 陰虛血燥 & Yin deficiency with blood dryness & 40 \\
\hline
\end{tabular}

participants), spleen deficiency with dampness accumulation脾虛濕蘊 (377 participants), spleen deficiency 脾 虛 (309 participants) and blood deficiency and wind-dryness 血虛風燥 (304 participants).

From the Chinese medicine perspective, the herbs used in the formulae generally have at least one of the following functions:

1. Fortifying the spleen and replenishing qi 健脾益氣 [e.g. Atractylodis Macrocephalae Rhizoma (Baizhu, 白术), Pseudostellariae Radix (Taizishen, 太子參)];

2. Inducing diuresis to drain dampness 利水滲濕 [e.g. Coicis Semen (Yiyiren, 薏药仁), Poria (Fuling, 获 苓)];

3. Clearing heat and drying dampness 清熱燥濕 [e.g. Phellodendri Chinensis Cortex (Huangbai, 黃柏), Scutellariae Radix (Huangqin, 黃芩)];

4. Dispersing wind and discharging heat 祛風泄熱 [e.g. Forsythiae Fructus (Lianqiao, 連堯羽), Dictamni Cortex (Baixianpi, 白鮮皮)];

5. Clearing heat to cool the blood 清熱涼血 [e.g. Mou$\tan$ Cortex (Mudanpi, 牡丹皮), Scrophulariae Radix (Xuanshen, 玄參)];

6. Tonifying blood 養血 [e.g. Angelicae Sinensis Radix (Danggui, 當歸), Paeoniae Radix Alba (Baishao, 白 苟)];

7. Nourishing yin滋陰 [e.g. Ophiopogonis Radix (Maidon, 麥冬), (Asparagi Radix (Tiandong, 天冬)];

8. Invigorating blood 活血 [e.g. Chuanxiong Rhizoma (Chuanxiong, 川芦), Persicae Semen (Taoren, 桃仁)].
The frequency of usage, functions and classifications of the top 20 most frequently used CHMs in the included studies were summarised in Table 2. These $20 \mathrm{CHMs}$ can be classified into 11 categories according to their main functions in Chinese medicine. They are, in descending order of their prescribing frequency: qi-tonifying 補氣藥, heat-clearing and dampness-drying 清熱燥濕藥, waterdraining and swelling-dispersing 利水消腫藥, wind-colddispersing 發散風寒藥, dampness-resolving 化濕藥, blood tonifying 補血藥, heat-clearing and blood-cooling 清熱涼血藥, stranguria-relieving diuretics 利尿通淋藥, qi-regulating 理氣藥, liver-pacifying 平抑肝陽藥, and heat-clearing and detoxicating 清熱解毒藥. These match well with the pathophysiology of $\mathrm{AD}$ in $\mathrm{CM}$ theory, i.e. accumulating dampness, heat and wind and the associated spleen qi deficiency that could result in blood deficiency if it persists into the chronic stage.

A total of 42 herbal formulae with specific names were identified in the included studies. The most commonly used formulae was Danggui Yinzi 當歸飲子, a blood tonifying and wind dispersing (養血社風) formula designed to resolve blood deficiency and wind-dryness (血虛風燥, which is a common CM syndrome in the chronic stage of $\mathrm{AD})$, with 4 studies using it as the main intervention.

\section{Risk of bias within studies}

About a third of included studies described an appropriate way of generating a random sequence (e.g. generation by computer software, coin tossing, random number table) and deemed to have low risk of bias in the domain of random sequence generation. Only 3 studies described 
Table 2 The top 20 most frequently used Chinese medicinal herbs in the included studies

\begin{tabular}{|c|c|c|c|}
\hline Chinese pinyin and character & Latin pharmaceutical name & $\begin{array}{l}\text { Frequency of } \\
\text { usage }\end{array}$ & $\begin{array}{l}\text { Classification based on main functions } \\
\text { (Chinese Materia Medica 7th edition) }\end{array}$ \\
\hline Fuling获苓 & Poria & 32 & $\begin{array}{l}\text { Water-draining and swelling-dispersing 利水消 } \\
\text { 腫藥 }\end{array}$ \\
\hline Baizhu白术 & Atractylodis Macrocephalae Rhizoma & 26 & Qi-tonifying 補氣藥 \\
\hline Gancao甘草 & Glycyrrhizae Radix et Rhizoma & 26 & Qi-tonifying 補氣藥 \\
\hline Baixianpi白鮮皮 & Dictamni Cortex & 25 & Heat-clearing and dampness-drying清熱燥濕藥 \\
\hline Huangqi黃芪 & Astragali Radix & 20 & Qi-tonifying 補氣藥 \\
\hline Cangzhu 蒼术 & Atractylodis Lancea Rhizoma & 19 & Dampness-resolving 化濕藥 \\
\hline Danggui當歸 & Angelicae Sinensis Radix & 18 & Blood tonifying 補血藥 \\
\hline Yiyiren薏蔌仁 & Coicis Semen & 17 & $\begin{array}{l}\text { Water-draining and swelling-dispersing 利水消 } \\
\text { 腫藥 }\end{array}$ \\
\hline Shengdihuang生地黃 & Rehmanniae Radix & 16 & Heat-clearing and blood-cooling 清熱涼血藥 \\
\hline Difuzi地膚子 & Kochiae Fructus & 15 & Strangury-relieving diuretic 利尿通淋藥 \\
\hline Jingjie荊芥 & Schizonepetae Herba & 15 & Wind-cold-dispersing 發散風寒藥 \\
\hline Fangfeng防風 & Saposhnikoviae Radix & 14 & Wind-cold-dispersing 發散風寒藥 \\
\hline Kushen苦參 & Sophorae Flavescentis Radix & 14 & heat-clearing and dampness-drying清熱燥濕藥 \\
\hline Chenpi陳皮 & Citri Reticulatae Pericarpium & 13 & Qi-regulating 理氣藥 \\
\hline Huangbai黃柏 & Phellodendri Chinensis Cortex & 12 & Heat-clearing and dampness-drying 清熱燥濕藥 \\
\hline Huangqin黃芩 & Scutellariae Radix & 12 & Heat-clearing and dampness-drying 清熱燥濕藥 \\
\hline Jili䓡藜 & Tribuli Fructus & 11 & Liver-pacifying 平抑肝陽藥 \\
\hline Dangshen黨參 & Codonopsis Radix & 10 & Qi-tonifying 補氣藥 \\
\hline Zexie澤瀉 & Alismatis Rhizoma & 10 & $\begin{array}{l}\text { Water-draining and swelling-dispersing 利水消 } \\
\text { 腫藥 }\end{array}$ \\
\hline Lianqiao連堛 & Forsythiae Fructus & 9 & Heat-clearing and detoxicating清熱解毒藥 \\
\hline Shanyao 山藥 & Dioscoreae Rhizoma & 9 & Qi-tonifying 補氣藥 \\
\hline
\end{tabular}

the allocation concealment method, and deemed to have low risk of bias in this domain [17-19]. Five studies took measures to blind participants, study personnel and outcome assessors [17-21]. Most of the studies (47 out of 55) had low risk of bias in incomplete outcome data. Most of the studies (53 out of 55) had unclear risk of bias in selective reporting because no relevant information was available. Overall, 2 studies $[17,18]$ were judged to have low risk of bias, 3 studies [19-21] had unclear risk of bias, and the other 50 studies had high risk of bias. Figure 2 shows the risk of bias graphs and summaries.

\section{Effects of interventions Primary outcomes}

Thirty-three studies measured clinical severity of atopic dermatitis by validated measurement scales. Among these, 18 [22, 24-29, 31, 32, 37-40, 42, 51, 54, 56, 57, 60, $68,69]$ used SCORAD and 8 [17, 20, 34, 46, 55, 63, 70, 75] used EASI. Seventeen studies [22, 25-29, 31, 32, 37-40, $42,51,54,56,57,60,68,69]$ using SCORAD and 5 [17, $34,55,70,75]$ using EASI were included in meta-analysis because of data availability. In both measures, ICWM was superior to WM alone (SCORAD: $\mathrm{MD}=-11.06,95 \% \mathrm{CI}$ -16.53 to -5.60 , participants $=1961, \mathrm{I}^{2}=99 \%$, Fig. 3a, effects of ICWM on the clinical severity of AD measured by SCORAD when compared with WM alone; EASI: $\mathrm{MD}=-2.68,95 \% \mathrm{CI}-4.95$ to -0.42 , participants $=371$, $\mathrm{I}^{2}=94 \%$, Fig. 3b, effects of ICWM on the clinical severity of AD measured by EASI when compared with WM alone). High heterogeneity was evidenced and possibly due to the varied interventions in these studies.

Furthermore, sensitivity analysis was conducted to examine the influence of study quality (including only study of low risk of bias) and that of using the change of score from the baseline rather than post-intervention scores as the outcome. The only study of low risk of bias [17] reported no significant difference between the ICWM and WM alone groups in the term of EASI change. When the change of score from baseline was used, with the missing SD of EASI imputed from figures reported in $\mathrm{Gu}$ et al. [17] and that of SCORAD imputed from Chen et al. [22], ICWM was still superior to WM alone (SCORAD: $\mathrm{MD}=-8.15,95 \% \mathrm{CI}-12.89$ to -3.41 ; EASI: $\mathrm{MD}=-2.59,95 \% \mathrm{CI}-4.48$ to -0.70 ).

Other measures included IGA [20], SASSAD [35, 36], Skin Severity Score by Japanese Dermatological Association [18] and 3 different kinds of author-defined clinical lesion/symptom scores [19, 33, 64]. Except for the 


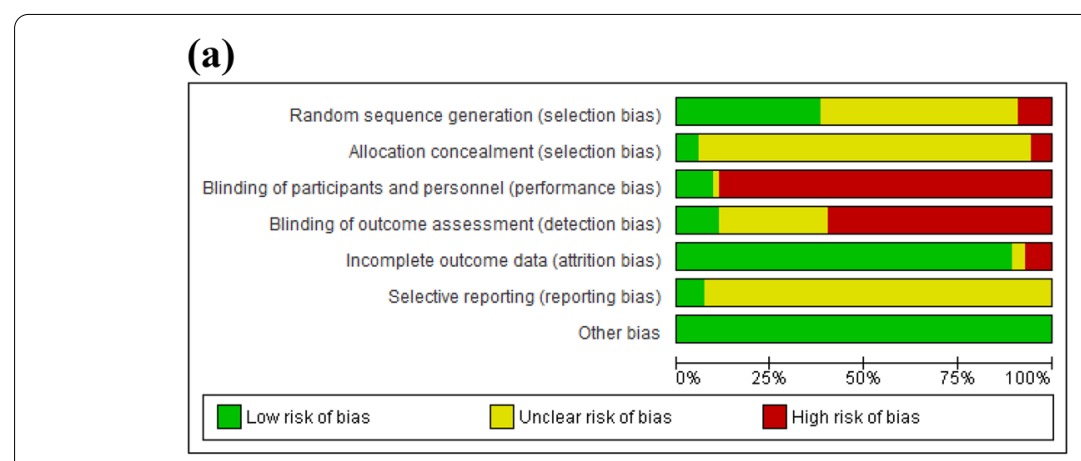

(b)
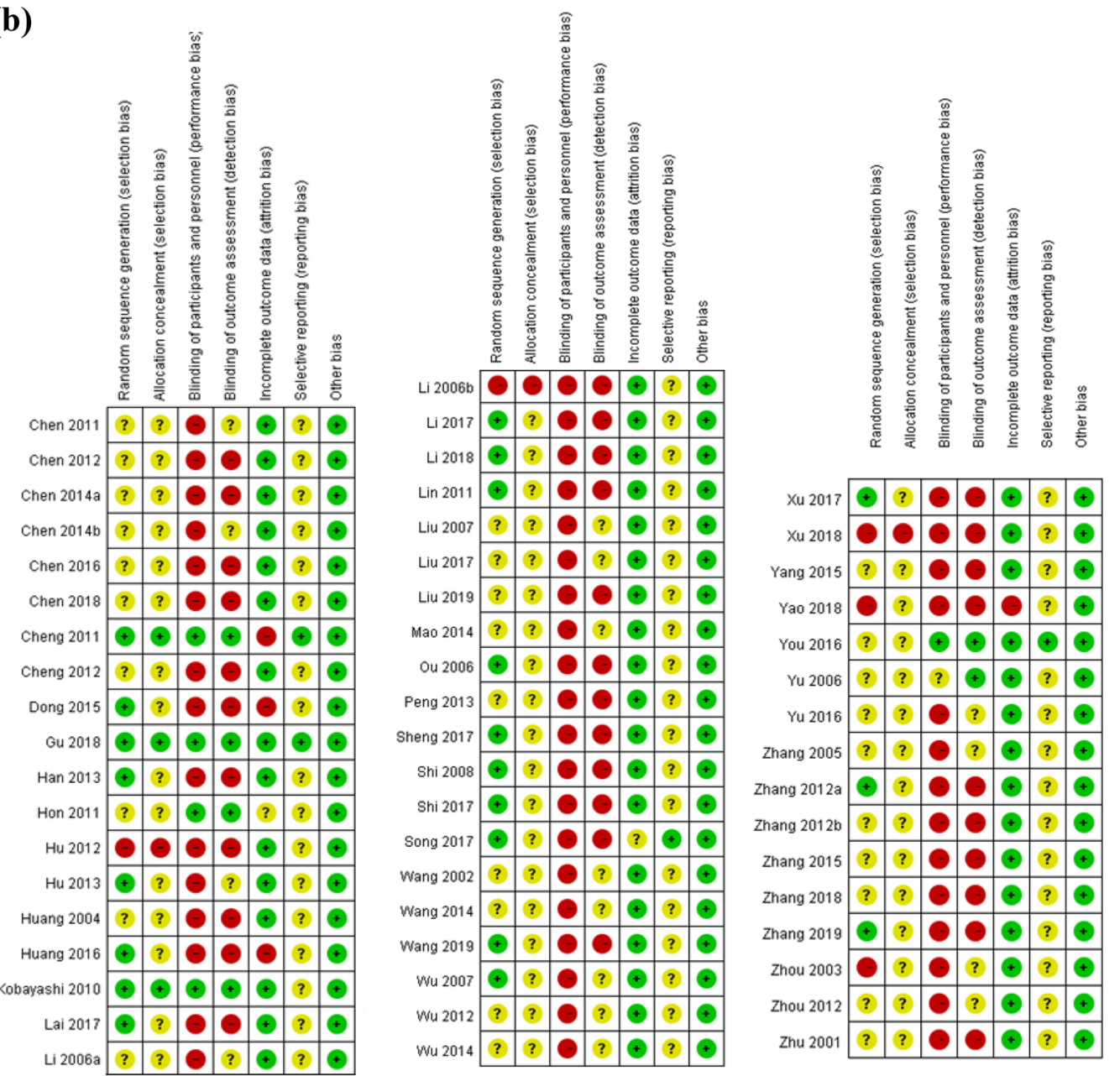

Fig. 2 a Risk of bias graph; $\mathbf{b}$ risk of bias summary

Japanese study applying IGA, which showed no significant difference between ICWM and WM groups in terms of IGA (with the amount of topical agents used in the WM group substantial higher than in ICWM group), all other studies indicated that ICWM was superior to WM in their respective measures.

\section{Secondary outcomes}

Participant-reported symptoms Six studies measured participant-reported symptoms by validated measurement scales. Among these, 5 used pruritus visual analogue scale (VAS) [20, 27, 28, 39, 46], of which 3 were included in the meta-analysis $[27,28,39]$. The result of meta-analysis showed no significant difference between the ICWM and 


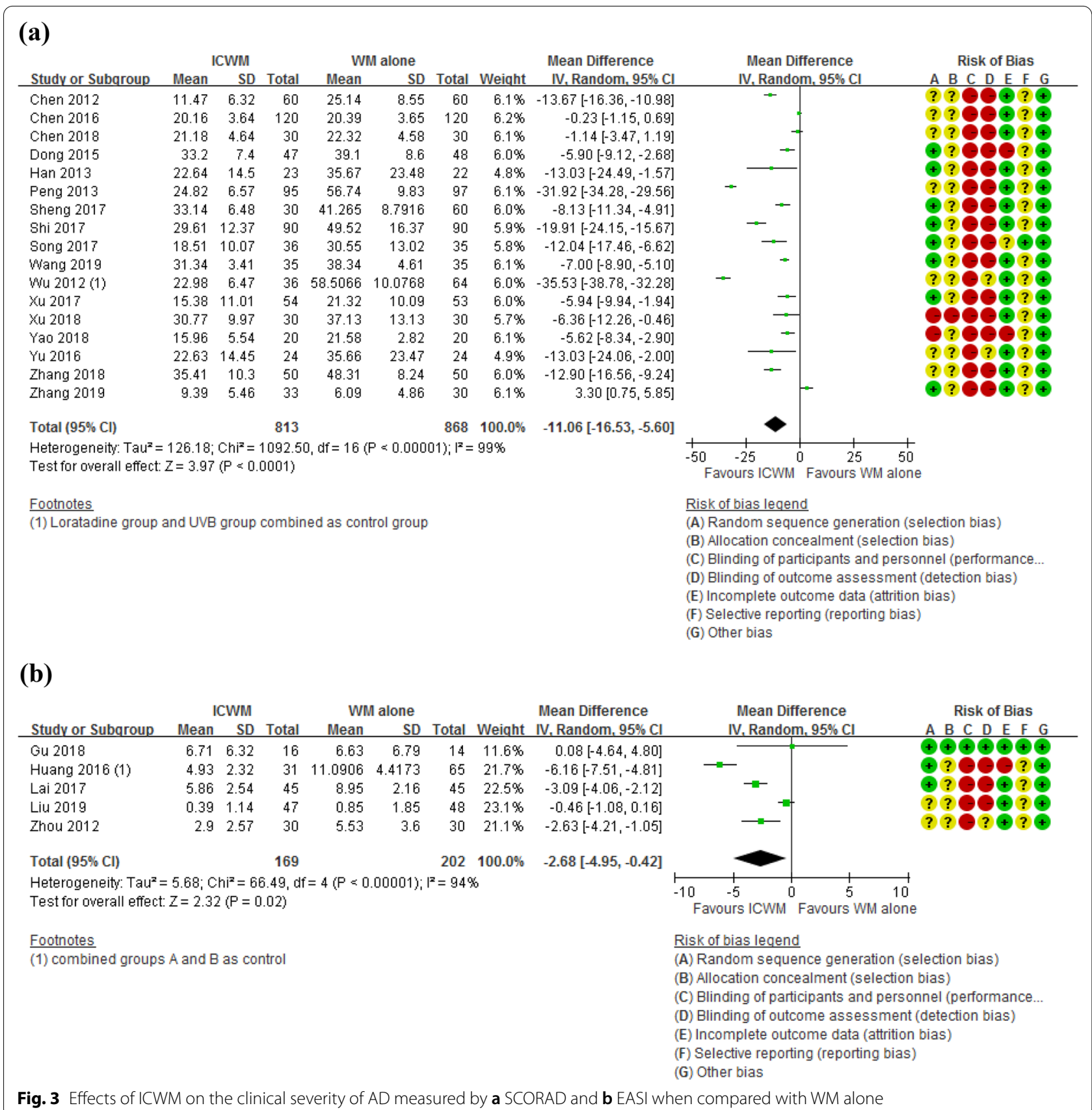

WM alone groups $(\mathrm{MD}=-1.21,95 \% \mathrm{CI}-2.45$ to 0.02 , participants $=203, \mathrm{I}^{2}=96 \%$ ). Only 1 study [17] measured participant-reported symptoms by POEM, and no significant difference was found between two groups.

Health-related quality of life Seven studies measured health-related quality of life by validated measure scales. Among these, 3 used only CDLQI $[17,24,55], 3$ used only DLQI $[23,54,70]$, and one used a score combined from both CDLQI and DLQI [31]. Two studies using only CDLQI $[17,55]$ and 3 studies using only DLQI were included in the meta-analysis. The study with combined score was not included for the meta-analysis as the scores were combined in an unspecified way and not separately available. In both measures, ICWM was superior to WM alone (CDLIQ: $\mathrm{MD}=-2.12,95 \% \mathrm{CI}-3.93$ to -0.31 , participants $=125, \mathrm{I}^{2}=1 \%$; DLQI: $\mathrm{MD}=-3.12, \quad 95 \%$ CI -5.03 to -1.22 , participants $=206, \mathrm{I}^{2}=94 \%$ ). However, sensitivity analysis showed no significant difference between groups in terms of CDLQI $(\mathrm{MD}=-1.41,95 \% \mathrm{CI}$ 
-3.84 to 1.02 ) when using change from baseline instead of post-intervention data, with missing SD imputed from Gu et al. [17].

Long-term control of atopic dermatitis (defined as the status of disease control at least 1 week after the end of intervention) Sixteen studies measured long-term control of AD [31-33, 39, 41, 47, 50, 51, 55, 58, 60, 63, 67, 69, 70, 75]. All were expressed in some forms of "cases of recurrence" or "recurrence rate" with observing intervals from 1 week to 1 year. The pooled analysis of 16 studies showed that ICWM was superior to WM alone in reducing recurrence rate $(\mathrm{RR}=0.47,95 \% \mathrm{CI} 0.38$ to 0.58 , participants $=1246$, $\left.\mathrm{I}^{2}=0 \%\right)$.

Percentage of trial participants with more than 50\% improvement in terms of patients or investigator global scores (clinical effectiveness rate) Most included studies in Chinese (49 out of 50) reported a set of ordinal percentage measures, such as no effect rate, effective rate, significantly effective rate, or complete recovery rate, which were based on different patient's or investigator's global scores, either validated (like EASI, SCORAD or SASSAD) or self-defined. For each study, we grouped subjects with more than $50 \%$ improvement in terms of global scores into one category, and those lower than $50 \%$ were grouped into another. Percentages of the former categories over the total sample sizes were defined as "clinical effectiveness rates" in this review, and meta-analyzed as a dichotomous outcome.

There were 4, 15, 5 and 24 studies which adopted EASI $[55,58,70,75]$, SCORAD [13, 22, 28, 29, 31, 32, 37, 38, $40,42,51,54,56,60,68,69]$, SASSAD [30, 36, 52, 61, 62] and other measures [23, 25, 27, 33, 34, 39, 41, 44-50, $53,59,62,64-67,71,72,74]$, respectively, as their basis for calculating the percentages. Meta-analyses were performed separately for these four groups. All four groups with different measures showed that ICWM was superior to WM alone in improving clinical effectiveness rate (EASI: $R R=1.30,95 \%$ CI 1.13 to 1.51 , participants $=307, \mathrm{I}^{2}=0 \%$, Fig. 4a; SCORAD: $\mathrm{RR}=1.46,95 \% \mathrm{CI}$ 1.24 to 1.72 , participants $=1547, \mathrm{I}^{2}=72 \%$, Fig. $4 \mathrm{~b}$; SASSAD: $\mathrm{RR}=2.50,95 \%$ CI 1.79 to 3.49 , participants $=311$, $\mathrm{I}^{2}=0 \%$, Fig. 4c; all other measures: $\mathrm{RR}=1.35,95 \% \mathrm{CI}$ 1.23 to 1.49 , participants $=2831, \mathrm{I}^{2}=77 \%$, Fig. $4 \mathrm{~d}$ ). The high heterogeneity in the SCORAD and other measurement groups was probably due to the diverse range of interventions involved.

Apart from the above, one English study [18] reported "prominent efficacy rate" (defined as the rate of subject with skin severity scoring 0 at the end of study). The difference between ICWM and WM alone groups was not significant (ICWM: 19\%, 7 of 37; WM alone: 5\%, 2 of 40; $\mathrm{P}=0.06)$.

Serum IgE level Twelve studies [19, 21, 24, 26, 30, 33, $40,53,58,62,64,71]$ measured serum IgE level. Among them, 10 studies [21, 26, 30, 33, 40, 53, 58, 62, 64, 71] were included in the meta-analysis. Pooled analysis showed that ICWM was superior to WM alone in attenuating IgE level $(\mathrm{MD}=-48.53 \mathrm{kU} / \mathrm{L}, 95 \% \mathrm{CI}-79.67$ to -17.38 , participants $=884, \mathrm{I}^{2}=80 \%$ ). The high heterogeneity was possibly due to the different interventions involved. For sensitivity analysis, if change from baseline data was used instead of post-intervention data, with missing SD imputed from figures report in the study Zhou et al. [64], ICWM would still be superior to WM alone in attenuating IgE level (MD $=-45.69 \mathrm{kU} / \mathrm{L}, 95 \% \mathrm{CI}-84.1$ to -7.29$)$.

Funnel plots were made for the outcomes that have at least 10 studies included in the meta-analysis. The pooled data on SCORAD, the percentages of trial participants with more than $50 \%$ improvement in terms of SCORAD or "other measures" as defined above, and serum IgE level were examined by funnel plots. Apart from the one with SCORAD, the plots were all highly asymmetrical, suggesting a significant risk in publication bias. (Fig. 5, funnel plots).

Adverse events Thirty-five (63.6\%) studies reported the occurrence of adverse events (AEs). Among these, 18 (32.7\%) [19, 22-24, 28, 29, 37, 38, 41, 44, 47, 49, 53, 56, 59-61, 64, 72] studies stated that no AEs were observed. For the other $17(30.9 \%)$ studies [17, 18, 20, 26, 27, 31, 33, $34,40,48,51,57,66,67,69,70,75]$, the reported adverse events for the ICWM group mainly included skin discomfort (such as rashes, pruritus, irritation, urticaria, local edema, xerosis) and gastrointestinal disturbance (like nausea, diarrhea, stomach discomfort, abdominal distension, epigastralgia, anorexia, loose stools). Other AEs included feeling of sleepiness, insomnia, dizziness, headache, conjunctivitis, common cold, upper respiratory infection, scabies, right hypochondriac pain, malaise, rhinitis, feverish thirst, dental caries, eosinophilia, GPT elevation, IgE elevation, blood urea nitrogen (BUN) accentuation and serum potassium elevation. Pooled analysis of 19 studies found no significant difference between ICWM and WM groups in the rate of adverse events $(R R=0.91,95 \% \mathrm{CI}$ 0.61 to 1.35 , participants $=1416, \mathrm{I}^{2}=47 \%$, Fig. 6 , effects of ICWM on the rate of adverse events when compared with WM alone). 
(a)

\begin{tabular}{|c|c|c|c|c|c|}
\hline \multirow{3}{*}{$\begin{array}{l}\text { Studv or Subqroup } \\
\text { Huang } 2016\end{array}$} & \multicolumn{2}{|c|}{ ICWM } & \multicolumn{2}{|c|}{ WM alone } & \\
\hline & Events & Total & Events & Total & Weial \\
\hline & 27 & 31 & 42 & 65 & $41.4 \%$ \\
\hline Liu 2007 & 24 & 29 & 15 & 27 & $14.9 \%$ \\
\hline Liu 2019 & 30 & 47 & 29 & 48 & $21.3 \%$ \\
\hline Zhou 2012 & 26 & 30 & 19 & 30 & $22.4 \%$ \\
\hline Total $(95 \% \mathrm{Cl})$ & & 137 & & 170 & $100.0 \%$ \\
\hline Total events & 107 & & 105 & & \\
\hline
\end{tabular}

Heterogeneity: $\mathrm{Tau}^{2}=0.00 ; \mathrm{Chi}^{2}=2.42, \mathrm{df}=3\left(\mathrm{P}^{2}=0.49\right) ; \mathrm{I}^{2}=0 \%$ Test for owerall effect: $Z=3.58(\mathrm{P}=0.0003)$

Risk of bias legend

(A) Random sequence generation (selection bias)

(B) Allocation concealment (selection bias)

(C) Blinding of participants and personnel (performance bias)

(D) Blinding of outcome assessment (detection bias)

(E) Incomplete outcome data (attrition bias)

(F) Selective reporting (reporting bias)

(G) Other bias

Risk Ratio Risk Ratio Risk of Bias

, Random, $95 \% \mathrm{Cl}$

$1.35[1.08,1.69]$

$1.49[1.02,2.17]$

$1.06[0.77,1.45]$

$1.37[1.01,1.86]$

$1.30[1.13,1.51]$

M-H, Random, 95\% Cl

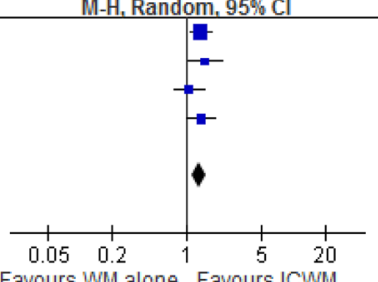

Favours WM alone Favours ICWM

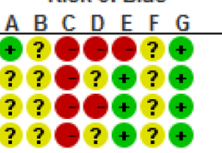

? ?९९?૯

(b)

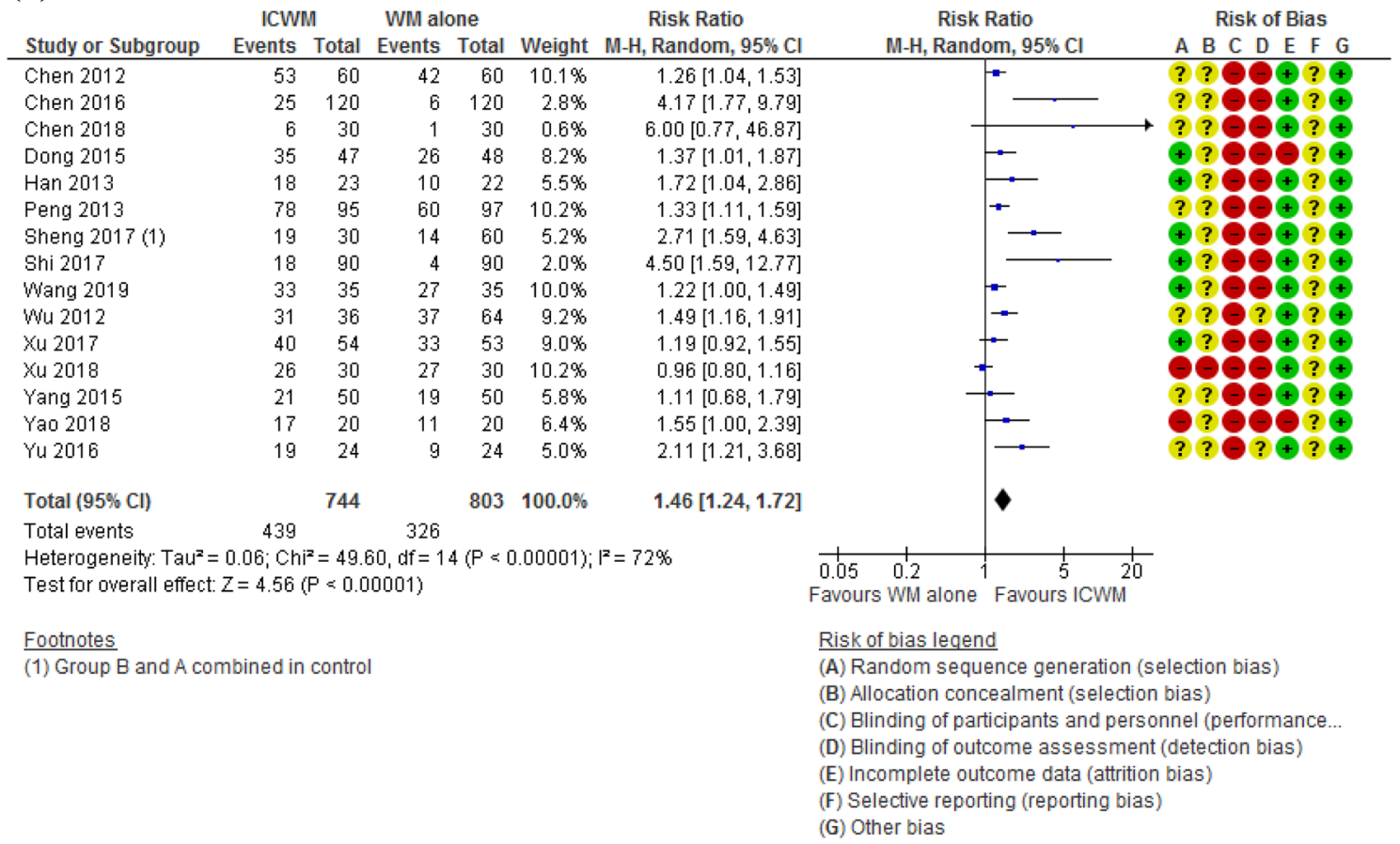

Fig. 4 Effects of ICWM on the percentage of trial participants with more than 50\% improvement in terms of a EASI, b SCORAD, c SASSAD and $\mathbf{d}$ all other measures when compared with WM alone 
(c)

\begin{tabular}{lll} 
ICWM WM alone & Risk Ratio \\
\hline
\end{tabular}

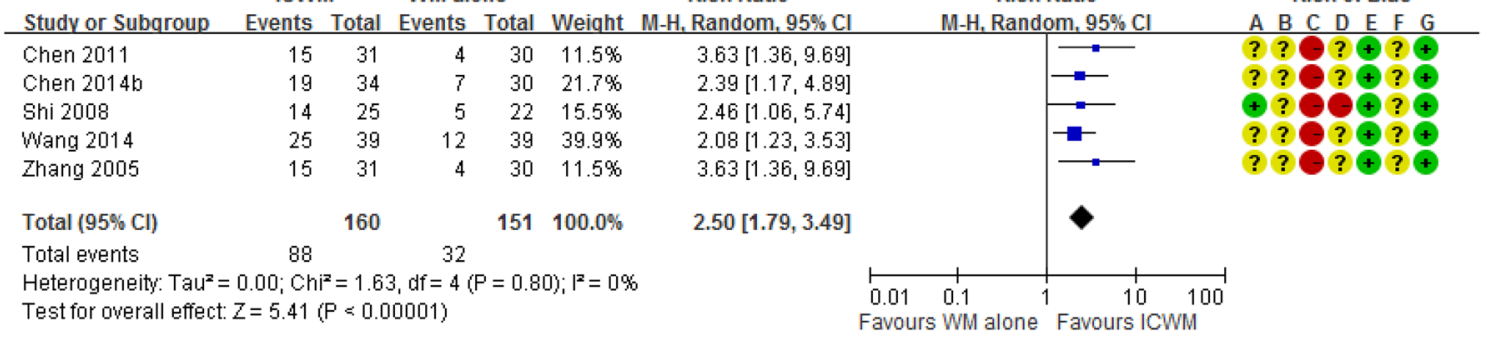

Risk of bias legend

(A) Random sequence generation (selection bias)

(B) Allocation concealment (selection bias)

(C) Blinding of participants and personnel (performance bias)

(D) Blinding of outcome assessment (detection bias)

(E) Incomplete outcome data (attrition bias)

(F) Selective reporting (reporting bias)

(G) Other bias

(d)

ICWM WM alone

Risk Ratio

Risk Ratio

Risk of Bias

\begin{tabular}{lrrrrrr} 
Studv or Subaroup & Events & Total & Events & Total & Weight & M-H. Random, 95\% Cl \\
\hline Chen 2014a & 27 & 33 & 8 & 33 & $1.7 \%$ & $3.38[1.81,6.30]$ \\
Cheng 2012 & 44 & 48 & 36 & 42 & $6.1 \%$ & $1.07[0.92,1.24]$ \\
Hu 2012 & 30 & 30 & 28 & 30 & $6.5 \%$ & $1.07[0.96,1.20]$ \\
Huang 2004 & 41 & 49 & 31 & 49 & $4.8 \%$ & $1.32[1.03,1.69]$ \\
Lai 2017 & 25 & 45 & 18 & 45 & $2.8 \%$ & $1.39[0.89,2.16]$ \\
Li 2006a & 31 & 38 & 20 & 38 & $3.7 \%$ & $1.55[1.11,2.17]$ \\
Li 2006b & 32 & 44 & 16 & 37 & $3.0 \%$ & $1.68[1.11,2.54]$ \\
Li 2017 & 17 & 34 & 7 & 31 & $1.4 \%$ & $2.21[1.06,4.61]$ \\
Li 2018 & 46 & 52 & 27 & 52 & $4.4 \%$ & $1.70[1.29,2.25]$ \\
Lin 2011 & 24 & 25 & 14 & 25 & $3.5 \%$ & $1.71[1.20,2.45]$ \\
Liu 2017 & 51 & 60 & 36 & 50 & $5.0 \%$ & $1.42[1.12,1.79]$ \\
Mao 2014 & 29 & 30 & 21 & 30 & $4.9 \%$ & $1.38[1.08,1.76]$ \\
Ou 2006 & 25 & 34 & 17 & 30 & $3.4 \%$ & $1.30[0.89,1.88]$ \\
Song 2017 & 22 & 36 & 11 & 35 & $2.1 \%$ & $1.94[1.12,3.39]$ \\
Wang 2002 & 634 & 648 & 200 & 270 & $6.9 \%$ & $1.32[1.23,1.42]$ \\
Wu 2003 & 118 & 119 & 77 & 85 & $6.9 \%$ & $1.11[1.03,1.19]$ \\
Mu 2014 & 26 & 43 & 8 & 29 & $1.7 \%$ & $2.19[1.16,4.15]$ \\
Zhang 2012a & 50 & 60 & 36 & 60 & $5.0 \%$ & $1.39[1.10,1.76]$ \\
Zhang 2012b & 18 & 21 & 9 & 21 & $2.2 \%$ & $2.00[1.18,3.38]$ \\
Zhang 2015 & 41 & 50 & 30 & 50 & $4.6 \%$ & $1.37[1.05,1.77]$ \\
Zhang 2018 & 47 & 50 & 38 & 50 & $5.8 \%$ & $1.24[1.04,1.47]$ \\
Zhang 2019 & 27 & 33 & 28 & 30 & $5.6 \%$ & $0.88[0.73,1.06]$ \\
Zhou 2003 & 28 & 41 & 16 & 32 & $3.1 \%$ & $1.37[0.91,2.05]$ \\
Zhu 2001 & 28 & 28 & 14 & 17 & $5.0 \%$ & $1.22[0.97,1.54]$ \\
& & & & & &
\end{tabular}

Total $(95 \% \mathrm{Cl})$

1650

Total events

1461

746

$1181 \quad 100.0 \% \quad 1.35[1.23,1.49]$

Heterogeneity: $\mathrm{Tau}^{2}=0.03 ; \mathrm{Chi}^{2}=102.05, \mathrm{df}=23(\mathrm{P} \approx 0.00001) ; \mathrm{I}^{2}=77 \%$

Test for owerall effect: $Z=6.28(P<0.00001)$

M-H, Random.

A B C D E F G

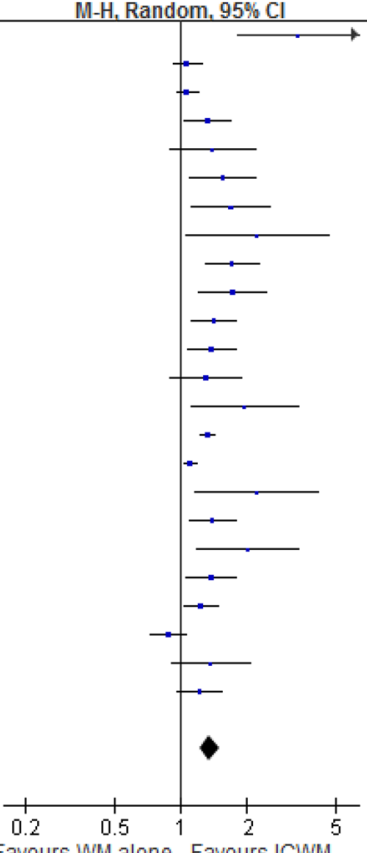

Favours WM alone Favours ICWM

?? ?80? ?

98+?+

? ?

4 ?

? ? ? ? ? +

९९९९) ? 4

+ ?Q⿱一⿻? ?

4 ?

๑) ?

? ?Q?૯? ?

? ? ?+? ?

๑) ?९९૯? ?

$\odot$ ?९९ ?๑४

? ?९?૯?+

๑ ?९?૯? ?

? ? ?๑?

+ ?

? ?

? ?

? ?

+ ?

?⿻? ? ?

? ?

Risk of bias legend

(A) Random sequence generation (selection bias)

(B) Allocation concealment (selection bias)

(C) Blinding of participants and personnel (performance bias)

(D) Blinding of outcome assessment (detection bias)

(E) Incomplete outcome data (attrition bias)

(F) Selective reporting (reporting bias)

(G) Other bias

Fig. 4 continued 


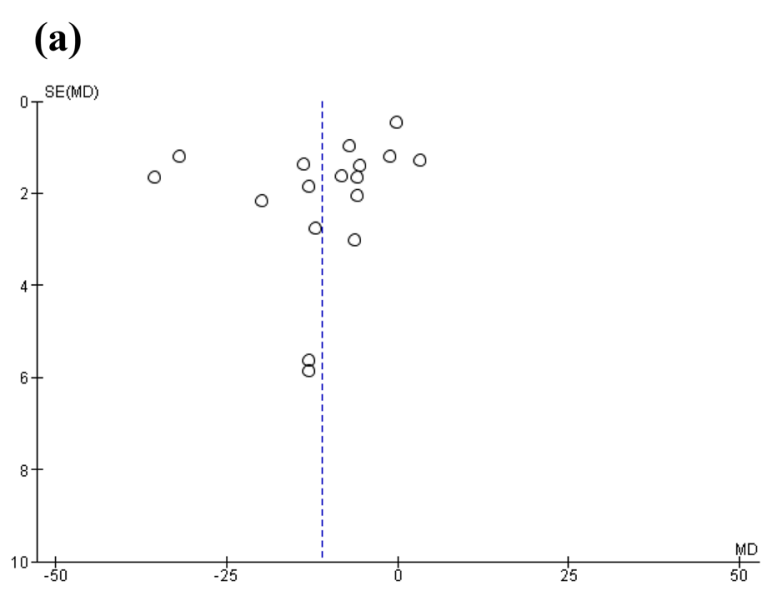

(b)

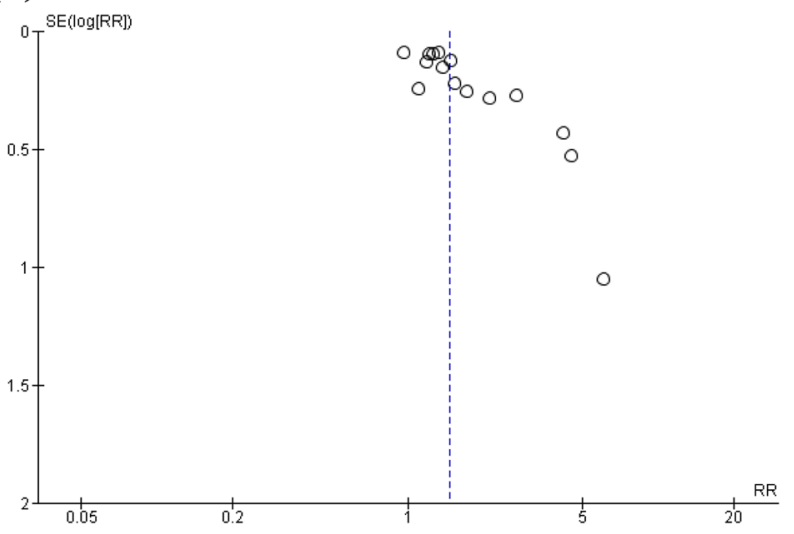

(c)

(d)
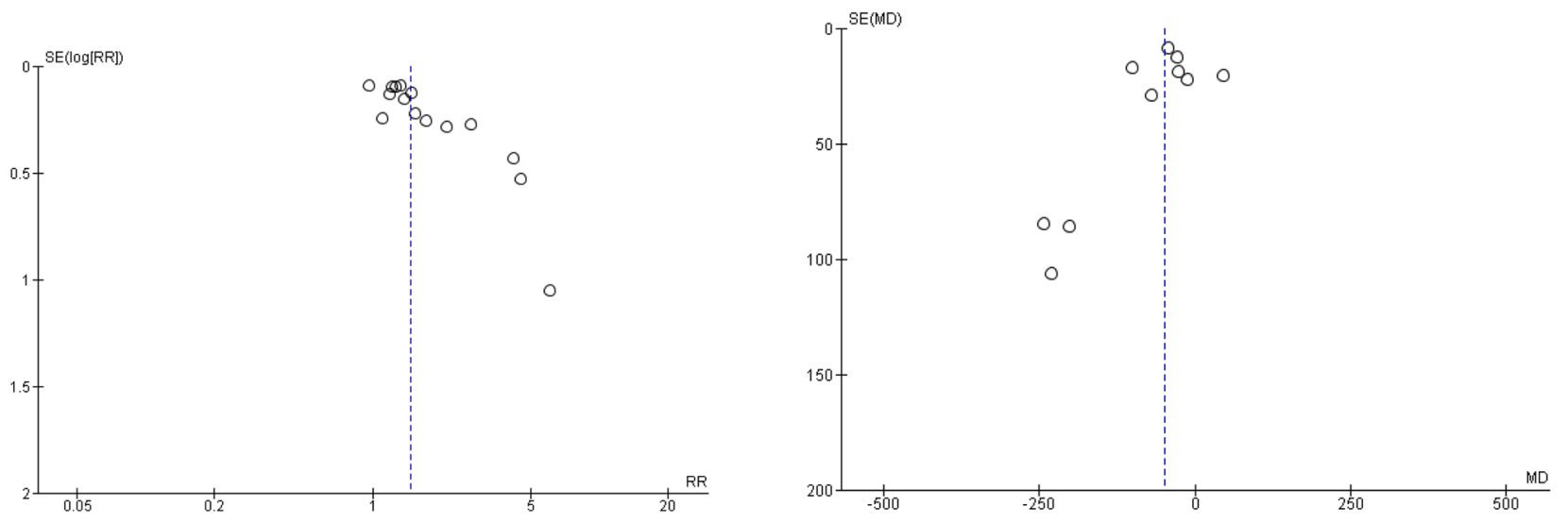

Fig. 5 Funnel plots for the meta-analysis of a SCORAD, $\mathbf{b}$ percentage of trial participants with more than $50 \%$ improvement in terms of patients or investigator global score (SCORAD), c percentage of trial participants with more than $50 \%$ improvement in terms of patients or investigator global score (all other measures), and $\mathbf{d}$ serum IgE level

\section{Discussion}

The present research findings suggested that ICWM was superior over WM alone in improving clinical severity of AD (as measured by EASI, SCORAD), health-related quality of life (as measured by CDLQI, DLQI), long term control of $\mathrm{AD}$ (recurrence rate), patients/investigator global score (effectiveness rate), and serum IgE level. We found no more adverse events associated with ICWM when compared with WM alone. However, some issues related to study quality weakened the strength of evidence, such as most studies having high risk of bias, conflicting results in some sensitivity analyses and potential publication bias.

The pathogenesis of AD is a complex interplay of multiple contributing factors, such as skin barrier defects, infections, immunological factors, susceptible genes (e.g., filaggrin genes) and environmental factors (e.g., food and aeroallergens, seasonal and climatic change) [7-9]. CM also considers different influencing factors when making syndrome diagnosis of $\mathrm{AD}$, albeit using different terminologies, such as damp-heat accumulation or spleen deficiency. A herbal formula is composed of herbs with different therapeutic functions to exert synergistic therapeutic actions. Experimental studies [78-82] have shown that many bioactive herbal ingredients from $\mathrm{CHMs}$, including Poria (Fuling, 获苓), Atractylodis Macrocephalae Rhizoma (Baizhu, 白术), Angelicae Sinensis Radix (Danggui, 當歸), Atractylodis Lancea Rhizoma (Cangzhu, 蒼术) and Dictamni Cortex (Baixianpi, 白鮮皮), exert anti-inflammatory, anti-allergic, antioxidative, and antiangiogenic effects. These active ingredients have been demonstrated to attenuate $\mathrm{AD}$ through diverse mechanisms such as restoring skin barriers, balancing Th1/Th2 cells levels, as well as regulating cytokine and chemokine expression, while have few side-effects [83, 84]. 


\begin{tabular}{|c|c|c|c|c|c|c|c|c|c|}
\hline \multirow[b]{2}{*}{ Study or Subgroup } & \multicolumn{2}{|c|}{ ICWM } & \multicolumn{2}{|c|}{ WM only } & \multirow[b]{2}{*}{ Weight } & \multirow{2}{*}{$\begin{array}{c}\text { Risk Ratio } \\
\text { M-H, Random, } 95 \% \mathrm{Cl}\end{array}$} & \multirow{2}{*}{\multicolumn{2}{|c|}{$\begin{array}{c}\text { Risk Ratio } \\
\mathrm{M}-\mathrm{H}, \text { Random, } 95 \% \mathrm{Cl} \\
\end{array}$}} & \multirow{2}{*}{$\begin{array}{l}\text { Risk of Bias } \\
\text { A B C D E F G }\end{array}$} \\
\hline & Events & Total & Events & Total & & & & & \\
\hline Gu 2018 & 3 & 16 & 0 & 14 & $1.7 \%$ & $6.18[0.35,110.11]$ & 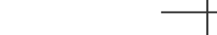 & & 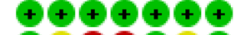 \\
\hline Han 2013 & 11 & 23 & 16 & 22 & $13.9 \%$ & $0.66[0.40,1.08]$ & $\rightarrow$ & & $+?$ \\
\hline Hu 2012 & 2 & 30 & 0 & 30 & $1.6 \%$ & $5.00[0.25,99.95]$ & & & \\
\hline Huang 2004 & 1 & 47 & 3 & 45 & $2.7 \%$ & $0.32[0.03,2.96]$ & & - & ?? \\
\hline Huang 2016 & 4 & 31 & 25 & 65 & $8.7 \%$ & $0.34[0.13,0.88]$ & & & ? ? + \\
\hline Kobayashi 2010 & 13 & 40 & 12 & 44 & $11.9 \%$ & $1.19[0.62,2.30]$ & & $=$ & 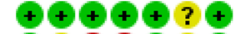 \\
\hline Lai 2017 & 4 & 45 & 2 & 45 & $4.4 \%$ & $2.00[0.39,10.38]$ & & & $\varphi+?$ \\
\hline Liu 2017 & 6 & 60 & 0 & 60 & $1.8 \%$ & $13.00[0.75,225.75]$ & & $\longrightarrow$ & ? ?९?๑?† \\
\hline Wao 2014 & 1 & 30 & 0 & 30 & $1.5 \%$ & $3.00[0.13,70.83]$ & & & ? ?९?†? \\
\hline Sheng 2017 & 1 & 30 & 2 & 30 & $2.5 \%$ & $0.50[0.05,5.22]$ & & & $?+$ \\
\hline Shi 2017 & 4 & 90 & 5 & 90 & $6.2 \%$ & $0.80[0.22,2.88]$ & & 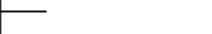 & $\oplus$ \\
\hline Mแ 2012 & 2 & 36 & 4 & 64 & $4.4 \%$ & $0.89[0.17,4.62]$ & & & ? ? \\
\hline Yang 2015 & 2 & 50 & 3 & 50 & $4.0 \%$ & $0.67[0.12,3.82]$ & & & ?? \\
\hline You 2016 & 34 & 55 & 20 & 59 & $14.9 \%$ & $1.82[1.21,2.75]$ & & $\rightarrow$ & $? ?+$ \\
\hline Yu 2016 & 10 & 24 & 16 & 24 & $13.2 \%$ & $0.63[0.36,1.08]$ & $\rightarrow$ & & ๑? \\
\hline Zhang 2019 & 1 & 39 & 6 & 38 & $3.1 \%$ & $0.16[0.02,1.29]$ & & 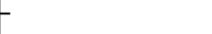 & +? ? \\
\hline Zhou 2012 & 2 & 30 & 2 & 30 & $3.5 \%$ & $1.00[0.15,6.64]$ & & & $? ?$ \\
\hline Total $(95 \% \mathrm{Cl})$ & & 676 & & 740 & $100.0 \%$ & $0.91[0.61,1.35]$ & & & \\
\hline Total events & 101 & & 116 & & & & & & \\
\hline $\begin{array}{l}\text { Heterogeneity: } \mathrm{Tau}^{2} \\
\text { Test for overall effect }\end{array}$ & $\begin{array}{l}0.23 ; \mathrm{Chi}^{-} \\
Z=0.47(\end{array}$ & $\begin{array}{l}\mathrm{P}^{2}=30.3 \\
\mathrm{P}=0.6\end{array}$ & $\begin{array}{l}38, d f=1 ! \\
\text { 4) }\end{array}$ & $6(P=0$ & $0.02) ; i^{2}=$ & $47 \%$ & $\begin{array}{ll}0.01 & 0.1 \\
\text { Favours ICWM } & 1\end{array}$ & 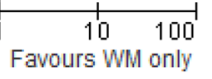 & \\
\hline $\begin{array}{l}\text { Risk of bias legend } \\
\text { (A) Random sequen } \\
\text { (B) Allocation concea } \\
\text { (C) Blinding of partici } \\
\text { (D) Blinding of outcor } \\
\text { (E) Incomplete outco } \\
\text { (F) Selective reportin } \\
\text { (G) Other bias }\end{array}$ & $\begin{array}{l}\text { Iment (sel } \\
\text { oants and } \\
\text { ne assess } \\
\text { me data (a } \\
\text { (reporting }\end{array}$ & $\begin{array}{l}\text { tion (se } \\
\text { lection } \\
\text { I persor } \\
\text { sment ( } \\
\text { attrition } \\
\text { g bias) }\end{array}$ & $\begin{array}{l}\text { election bi } \\
\text { bias) } \\
\text { nnel (perf } \\
\text { (detection } \\
\text { bias) }\end{array}$ & $\begin{array}{l}\text { bias) } \\
\text { forman } \\
\text { n bias) }\end{array}$ & ce bias) & & & & \\
\hline Fig. 6 Effects of ICWN & I on the ra & ate of a & adverse e & events $\mathrm{V}$ & when cc & ared with WM alone & & & \\
\hline
\end{tabular}

The possible interaction between Chinese medicines and WM is one of the serious concerns about clinical safety. In this review, we found no significant difference in the occurrence of AEs between ICWM and WM. Our finding is congruent with previous reports that the combination of ICWM did not evoke additional adverse events [85]. It has also been reported that adding CHMs might have reduced the occurrence of adverse events of conventional pharmacotherapy such as skin dryness, skin itchiness, dry mouth/lips, and dry/scaly skin [86]. Different herbs and pharmacotherapies may be involved in the possible interaction. As CHMs can affect the pharmacokinetic properties of WMs, close attention should be paid to the possible interactions between CHMs and WMs.

To the best of our knowledge, this review is the first of its kind to systematically summarise and analyse the ICWM for AD. The comprehensive search strategy, scientifically robust way to assess risk of bias and the subsequent meta-analysis made the generation of findings more reliable. The low methodological quality and poor reporting are the main problems associated with many included studies which weakened the evidence. No proper blinding is another main methodological problem found in many included studies. As the main outcomes for evaluating the treatment effect for AD are most subjective, the blinding is a very important strategy to reduce possible bias and subjective influences. Additionally, no clear description of random generation and allocation concealment were commonly found in most of the included studies. Further clinical studies with high methodological quality are badly needed to consolidate the evidence about the ICWM for AD management.

\section{Conclusions}

Adopting ICWM was found to be superior to using WM alone in improving clinical symptoms and quality of life, and reducing the recurrence rate in the patients with atopic dermatitis. In addition, addition of CHMs to conventional western treatment presented no more adverse effect than WM alone. However, due to the methodological limitations in the included studies and possible publication bias, we could not draw a definitive conclusion about the effectiveness and safety of ICWM for the treatment of AD. In this connection, more methodologically rigorous clinical trials are urgently needed to generate quality clinical evidence about the routine use of ICWM in the management of atopic dermatitis. 


\begin{abstract}
Abbreviations
AD: Atopic dermatitis; ICWM: Integrated Western-Chinese medicine; WM: Western medicine; CHM: Chinese herbal medicines; RCT: Randomised controlled trials; EASI: Eczema area and severity index; SCORAD: Scoring atopic dermatitis; SASSAD: Six area, six sign atopic dermatitis; IGA: Investigators' global assessment; BSA: Body surface area; POEM: Patient-oriented eczema measure; VAS: Visual analogue scale; DLQL: Dermatology life quality index; CDLQI: Children's dermatology life quality index; RR: Risk ration; Cl: Confidence intervals; pCm: Proprietary Chinese medicine; AEs: Adverse events; BUN: Blood urea nitrogen.
\end{abstract}

\section{Acknowledgements \\ Not applicable.}

\section{Authors' contributions}

$C J, L S, Y C L$ and LZX organized and conceived the study. SCH, LCW, LMK, CPK, and LZX searched and screened the studies. SCH, LCW, and ZHW assessed the risk of bias. $\mathrm{SCH}, \mathrm{CJ}, \mathrm{LS}$, and $\mathrm{ZHW}$ performed the data analysis. $\mathrm{SCH}, \mathrm{CJ}$, LZX and ZHW drafted the manuscript. All authors read and approved the final manuscript.

\section{Funding}

This study was funded by the Innovative Technology Commission of the Government of Hong Kong Special Administrative Region and Dr. Barbara Kwok Integrative Medicine Research Fund. The Integrative Joint Organizational Platform (IJOP) created this systematic review (SR) project under the management of the Hong Kong Association for Integration of Chinese-Western Medicine ("Association") that appointed a tertiary academic institution ("Institution") to conduct this SR. Dr. Barbara Kwok Integrative Medicine Research Fund, under the management of the Hong Kong Institute of Integrative Medicine, The Chinese University of Hong Kong, partially supported this project.

\section{Availability of data and materials}

Not applicable.

\section{Declarations}

Ethics approval and consent to participate

Not applicable.

\section{Consent for publication}

Not applicable.

\section{Competing interests}

The authors declare that they have no competing interests.

\section{Author details}

${ }^{1}$ Hong Kong Institute of Integrative Medicine, The Chinese University of Hong Kong, Shatin, N.T., Hong Kong, China. ${ }^{2}$ School of Chinese Medicine, Faculty of Medicine, The Chinese University of Hong Kong, Shatin, N.T., Hong Kong, China.

Received: 2 July 2021 Accepted: 17 September 2021 Published online: 10 October 2021

\section{References}

1. Thomsen SF. Atopic dermatitis: natural history, diagnosis, and treatment. ISRN Allergy. 2014;2014: 354250. https://doi.org/10.1155/2014/354250.

2. Mayba JN, Gooderham MJ. Review of atopic dermatitis and topical therapies. J Cutan Med Surg. 2017;21(3):227-36.

3. DaVeiga SP. Epidemiology of atopic dermatitis: a review. Allergy Asthma Proc. 2012;33(3):227-34

4. Mansouri Y, Guttman-Yassky E. Immune pathways in atopic dermatitis, and definition of biomarkers through broad and targeted therapeutics. J Clin Med. 2015;4(5):858-73.
5. The Hong Kong Allergy Association. Eczema 2014. http://www.allergyhk. org/?page_id=317. Accessed 20 May 2020.

6. Stander S. Atopic dermatitis. N Engl J Med. 2021;384(12):1136-43.

7. Narla S, Silverberg Jl. The role of environmental exposures in atopic dermatitis. Curr Allergy Asthma Rep. 2020;20(12):74.

8. Langan SM, Irvine AD, Weidinger S. Atopic dermatitis. Lancet. 2020;396:345-60.

9. Kapur S, Watson W, Carr S. Atopic dermatitis. Allergy Asthma Clin Immunol. 2018;14(Suppl 2):52.

10. Schäfer T. Complementary and alternative medicine (CAM) and atopic eczema. Allergol Select. 2017;1 (1):44-52.

11. Gu S, Yang AW, Xue CC, Li CG, Pang C, Zhang W, et al. Chinese herbal medicine for atopic eczema. Cochrane Database Syst Rev. 2013;9:D8642.

12. Gu SX, Zhang AL, Coyle ME, Chen D, Xue CC. Chinese herbal medicine for atopic eczema: an overview of clinical evidence. J Dermatol Treat. 2017;28(3):246-50.

13. Shi Z, Song T, Xie J, Yan Y, Du Y, Deyhim F. The traditional Chinese medicine and relevant treatment for the efficacy and safety of atopic dermatitis: a systematic review and meta-analysis of randomised controlled trials. Evid Based Complement Alternat Med. 2017;2017:6026434. https://doi. org/10.1155/2017/6026434

14. Brenninkmeijer EE, Schram ME, Leeflang MM, Bos JD, Spuls PI. Diagnostic criteria for atopic dermatitis: a systematic review. Br J Dermatol. 2008;158(4):754-65.

15. Higgins JPT, Green S, editors. Cochrane handbook for systematic reviews of interventions version 5.1.0. The Cochrane Collaboration, 2011. www. handbook.cochrane.org. Accessed Mar 2011.

16. Liberati A, Altman DG, Tetzlaff J, Mulrow C, Gøtzsche PC, loannidis JP, et al. The PRISMA statement for reporting systematic reviews and metaanalyses of studies that evaluate health care interventions: explanation and elaboration. PLoS Med. 2009;6(7): e1000100. https://doi.org/10.1371/ journal.pmed.1000100.

17. Gu SX, Mo X, Zhang AL, Liu J, Coyle ME, Ye S, et al. A Chinese herbal medicine preparation (Pei Tu Qing Xin) for children with moderate-tosevere atopic eczema: a pilot randomised controlled trial. Brit J Dermatol. 2018;179(6):1404-5.

18. Kobayashi H, Ishii M, Takeuchi S, Tanaka Y, Shintani T, Yamatodani A, et al. Efficacy and safety of a traditional herbal medicine, Hochu-ekki-toin the long-term management of Kikyo (delicate constitution) patients with atopic dermatitis: a 6-month, multicenter, double-blind, randomised, placebo-controlled study. Evid Based Complement Alternat Med. 2010;7(3):367-73.

19. Cheng HM, Chiang LC, Jan YM, Chen GW, Li TC. The efficacy and safety of a Chinese herbal product (Xiao-Feng-San) for the treatment of refractory atopic dermatitis: a randomised, double-blind, placebo-controlled trial. Int Arch Allergy Immunol. 2011;155(2):141-8.

20. You CE, Moon SH, Lee KH, Kim KH, Park CW, Seo SJ, et al. Effects of emollient containing bee venom on atopic dermatitis: a double-blinded, randomised, base-controlled, multicenter study of 136 patients. Ann Dermatol. 2016;28(5):593-9.

21. YuT, Chen BJ, Wang P, Zhang YH. Effect of therapy fortifying the spleen and tonifying the kidney on serum total IgE level in patients with atopic dermatitis. Jilin J Tradit Chin Med [Jilin Zhong Yi Yao]. 2006;9:15-7 (In Chinese).

22. Chen JH, Xiu MY, Yang ML. Observation on therapeutic effect of external application of Jinyu Waixi formula on children with atopic dermatitis. Chin Manip Rehabil Med [Anmo Yu Kangfu Yi Xue]. 2016;21:33-5 (In Chinese).

23. Cheng HM, Chiang LC, Jan YM, Chen GW, LiTC. The efficacy and safety of a Chinese herbal product (Xiao-Feng-San) for the treatment of refractory atopic dermatitis: a randomized, double-blind, placebo-controlled trial. Int Arch Allergy Immunol. 2011;155(2):141-8.

24. Hon KLE, Leung TF, Lam MCA, Kam WYC, Wong KY, Lee KCK, et al. Therapeutic effect and safety of a traditional Chinese medicine for atopic dermatitis in children: a randomised, double-blind, placebo-controlled study. Hong Kong Med J. 2011;17(Suppl 2):38-40.

25. Zhang CS. Therapeutic effect of modified Baohe pills of infant eczema: an observation of 21 cases. J New Chin Med [Xin Zhong Yi]. 2012;44(12):76-7 (In Chinese). 
26. Shi H. TCM syndrome characteristics of children with atopic dermatitis and clinical effect of Chinese herbal medicine. Guangming J Chin Med [Guangming Zhong Yi]. 2017;4:468-70 (In Chinese).

27. Zhang LY, Li YW, Lin HE, Tu SZ, Peng J, Liu YJ, et al. Clinical efficacy of compound oleum lithospermi combined with loratadine in the treatment of mild to moderate atopic dermatitis. World Chin Med [Shijie Zhong Yi Yao]. 2019:014(6):1511-5 (In Chinese).

28. Yao XY. Clinical observation on treatment of moderate to severe atopic dermatitis with modified spleen strengthening and heart clearing formula and its evaluation of itching improvement. Master thesis. Nanjing University of Chinese Medicine; 2018. (In Chinese).

29. Dong XY, Zhou J. Effect of Jianpihuashitang combined with hydrocortisone butyrate cream on atopic dermatitis. Guangdong Med J [Guangdong Yi Xue]. 2015;22:3540-2 (In Chinese).

30. Chen BJ, Zhang YH. Observation on the therapeutic effect of Jianpi Lishi decoction on atopic dermatitis and related experimental research. Jilin J Tradit Chin Med [Jinlin Zhong Yi Yao]. 2011;04:335-6 (In Chinese).

31. Sheng YL. Clinical observation on treatment of atopic dermatitis with JianPi QuFeng method combined with skin barrier repair milk. Master thesis. Anhui University of Chinese Medicine; 2017. (In Chinese).

32. Peng Y, Li B, Li F, Wang YJ, Wu ZQ, Chai WH. Clinical effect of Jianpi Qufeng decoction in treating 95 patients with atopic dermatitis. J Shanghai Univ Tradit Chin Med [Shanghai Zhong Yi Yao Da Xue Xue Bao]. 2013;27(3):45-7 (In Chinese).

33. Huang YJ, Chen DC, Mo XM. Clinical observation of Jianpi Dushi granules in treating children with atopic dermatitis and spleen deficiency syndrome. Shaanxi J Tradit Chin Med [Shaanxi Zhong Yi]. 2004;25(5):396-8 (In Chinese).

34. Lai YQ, Shi XY. Observation on therapeutic effect of fortifying the spleen and draining dampness combined with tacrolimus on atopic dermatitis. Shaanxi J Tradit Chin Med [Shaanxi Zhong Yi]. 2017;38(10):1445-6 (In Chinese).

35. Lin SC. Treatment of spleen deficiency type of atopic dermatitis clinical observation. Master thesis. Guangzhou University of Chinese Medicine; 2011. (In Chinese)

36. Wang JZ, Xi W, Tong XH, Liu C. Detoxification moisturizing decoction in the treatment of atopic dermatitis. Chin J InfTradit Chin Med [Zhong Yi Yao Xin Xi]. 2014;5:111-3 (In Chinese)

37. Chen $J H, H e X Y$. Therapeutic effect of Jin Yu Waixi recipe for pediatric atopic dermatitis children with different traditional chinese medical constitutions. J Guangzhou Univ Tradit Chin Med [Guangzhou Zhong Yi Yao Da Xue Xue Bao]. 2017;01:35-9 (In Chinese).

38. Chen JH, Pan PG, Fan RQ, Chen XY, Wang X, Xu LP. Clinical study on Jinyu Waixi formula for treatment of dampness-heat atopic eczema in children. J New Chin Med [Xin Zhong Yi]. 2012;44(8):113-5 (In Chinese).

39. Zhang LY, Tan XH, Yang L, Ma Y. Effect of Ku Shen tea combined with ultraviolet irradiation on skin barrier function and immune function in patients with atopic dermatitis. ACTA Chin Med [Zhong Yi Xue Bao]. 2018;33(3):488-91 (In Chinese)

40. Wu BL, Cao Y, Chen LF, Yang XH, Suan J, Wei S. Influence of Piyan Xiaojin Decoction II combining with narrow-band UVB exposure on cellular adhesion molecules expression and total IgE level in atopic dermatitis patients. China J Tradit Chin Med Pharm [Zhonghua Zhong Yi Yao Za Zhi]. 2012;27(5):1317-20 (In Chinese).

41. Cheng XC, Yue DR. Observation on the curative effect of Pingweibaohewan granules on infantile eczema. J Sichuan Tradit Chin Med [Sichuan Zhong Yi]. 2012;30(12):100-1 (In Chinese).

42. Chen JH, Fan RQ, Chen XY, Wang X, Xu LP. The effect of self-made Jinyu Waixi formula on the severity of atopic eczema skin lesions in childrenan introduction. Seek Med Ask Med [Qiu Yi Wen Yao]. 2012;05:319-20 (In Chinese).

43. Wu DS, Liang Y. A comparative study of adjuvant treatment for atopic dermatitis in infant with natural indigo. Chin J Tradit West Med [Zhong Hua Zhong Xi Yi Za Zhi]. 2003;4(2):195-6 (In Chinese).

44. Wu DS, Liang Y, Li Y, Xuan HM, Shu HW. A comparative study of adjuvant treatment for atopic dermatitis in infant with natural indigo. Public Med Forum Mag (Ji Ceng Yi Xue Lun Tan). 2007;11(10):869-70 (In Chinese).

45. Wang LH, Zhou LB. Clinical observation on 648 cases of infantile allergic eczema treated by "heat-clarifying and dampness-removing mixture." J Shanghai Univ Tradit Chin Med [Shanghai Zhong Yi Yao Da Xue Xue Bao]. 2002;16(1):26-7 (In Chinese).
46. Li XZ, Xu P, Pan WD, Zhang HM. Clinical research of Qufeng Lishi mixture in treating fengshi yunfu-type atopic dermatitis. China Med Her [Zhongguo Yi Yao Dao Bao]. 2017;14(22):101-4 (In Chinese).

47. Chen QH, Yuan Y. Clinical study on treatment of infantile eczema with external application of Qushifang. Chin Manip Rehabil Med [Anmo Yu Kangfu Yi Xue]. 2014;5(5):87-8 (In Chinese).

48. Mao JJ, Zhu MF, Zhang XL. Clinical efficacy of pomegranate rind ointment in treatment of atopic dermatitis: a report of 30 cases. Hunan J Tradit Chin Med [Hunan Zhong Yi Za Zhi]. 2014(4):2-24, 29. (In Chinese).

49. Ou BS, Liu WB, Wang JM. 34 cases of atopic dermatitis treated by Siwanfeng decoction combined with western medicine. China's Naturop [Zhongguo Min Jian Liao Fa]. 2006;01:8-9 (In Chinese).

50. Li YY. Observation of curative effect of modified Xiaofeng powder on children with eczema. J Dermatol Venereol [Pifu Bing Yu Xing Bing]. 2018;40(1):109-11 (In Chinese).

51. Yang $\mathrm{YH}$. Study on clinical effect of TCM intervention in treating blood deficiency and wind dryness type atopic dermatitis. Guangming J Chin Med [Guangming Zhong Yi]. 2015;4:753-5 (In Chinese).

52. Chen BJ. Clinical efficacy of Yangxue Jianpi Runfu method in treating patients with atopic dermatitis and its influences on serum levels of interleukin-18. Chin J Dermatovenerol Integr Tradit West Med [Zhongguo Zhong Xi Yi Ji He Pi Fu Xing Bing Xue Za Zhi]. 2014;5:283-5 (In Chinese)

53. Song XL. Clinical observation on treatment of atopic dermatitis and its influence on IgE by nourishing blood and expelling wind decoction. Heilongjiang Univ Chin Med [Heilongjiang Zhong Yi Yao Da Xue]; 2017. (In Chinese).

54. Xu ZJ. Clinical observation on treatment of 30 cases of atopic dermatitis with Yangxue Runfu decoction and Xiluotuo. Hunan J Tradit Chin Med [Hunan Zhong Yi Za Zhi]. 2018;34(8):7-78, 83. (In Chinese).

55. Liu WJ. Clinical observation on Yupingfeng granules for treatment of infantile atopic dermatitis. J Guangzhou Univ Tradit Chin Med [Guangzhou Zhong Yi Yao Da Xue Xue Bao]. 2019;36(6):800-4 (In Chinese).

56. Xu JQ, Chen S. Clinical observation on children atopic dermatitis with dampness-heat syndrome treated with integrated traditional Chinese and western medicine. J North Pharm [Bei Fang Yao Xue]. 2017;14(8):9-10 (In Chinese).

57. Yu JB, Wang Q, Li JN. Observation on the therapeutic effect of integrated traditional Chinese and western medicine on children with atopic dermatitis. Chin J Tradit Med Sci Technol [Zhongguo Zhong Yi Yao Ke Ji]. 2016;2:219-20 (In Chinese)

58. Liu Y, Ye QH, Chen JY, He Q, Wang YM, Wei KF. Clinical study on treatment of childhood atopic dermatitis with integrated Chinese and western medicine. J Nanjing TCM Univ [Nanjing Zhong Yi Yao Da Xue Xue Bao]. 2007;02:93-5 (In Chinese).

59. Li F, Luo WH. A summary of 44 cases of atopic dermatitis treated with integrated Chinese and western medicine. Hunan J Tradit Chin Med [Hunan Zhong Yi Za Zhi]. 2006;22(4):20-1 (In Chinese).

60. Wang YS. Clinical observation on atopic dermatitis treated with integrated Chinese and western medicine. China's Naturop [Zhongguo Min Jian Liao Fa]. 2019;04:73-4 (In Chinese).

61. Shi YJ, Zhang CM, Ma DM, Liu Y, Zhang DY, Zhang CH. Clinical study on treatment of atopic dermatitis by integrated traditional Chinese and western medicine. Chin J Integr Tradit West Med [Zhongguo Zhong Xi Yi Jie He Za Zhi]. 2008;28(8):686-8 (In Chinese).

62. Zhang $\mathrm{YH}$, Chen BJ. Clinical study of integrated traditional Chinese and western medicine for the treatment on atopic dermatitis. Chin J Dermatovenerol Integr Tradit West Med [Zhongguo Zhong Xi Yi Ji He Pi Fu Xing Bing Xue Za Zhi]. 2005;4(4):207-10 (In Chinese).

63. Hu YS, Zhang BX, Guo YP. Random control study on treating AD in the integrative medicine. Clin J Chin Med [Zhong Yi Lin Chuang Yan Jiu]. 2013;5(3):10-2 (In Chinese).

64. Zhou ZM. Combined TCM and west medicine to treating 41 cases of atopie dermatitis. Hunan Guid J TCMP [Huan Zhong Yi Yao Dao Bao]. 2003:9(3):34-5 (In Chinese).

65. Zhu CY. Observation of therapeutic effect of integrated Chinese and western medicine on atopic dermatitis. J Modern Med Health [Xiandai Yi Yao Wei Sheng]. 2001;05:368 (In Chinese).

66. Hu NN, Wang XF, Zhao X. Clinical observation on infantile eczema treated with integrated Chinese and western medicine. Liaoning J Tradit Chin Med [Liaoning Zhong Yi Za Zhi]. 2012;39(7):1354-5 (In Chinese). 
67. Liu G, Wang Q. Observation on treating AD by TCM medicine umbilical therapy. Clin J Chin Med [Zhong Yi Lin Chuang Yan Jiu]. 2017;19:123-4 (In Chinese).

68. Chen JH, Ye GF, Xiu MY. Study on the curative effect of external application of traditional Chinese medicine on 1-6 years old children of spleen deficiency body constitution with atopic dermatitis. Chin Manip Rehabil Med [Anmo Yu Kangfu Yi Xue]. 2018;9(9):44-6 (In Chinese).

69. Han HJ, Guo F, Liu HX. Efficacy and safety observation of Chinese medicine bath joint tacrolimus ointment for the treatment of children with atopic dermatitis. Chin J Dermatovenerol Integr Tradit West Med [Zhongguo Zhong Xi Yi Ji He Pi Fu Xing Bing Xue Za Zhi]. 2013;12(3):164-6 (In Chinese).

70. Huang WH, Wang CM. Curative effect of TCM medicated bath combined with tacrolimus on moderate to severe atopic dermatitis in children and influence on serum LTB4 on LTC4. Chin J Gen Pract [Zhonghua Quan Ke Yi Xue]. 2016;4:60-606 (In Chinese).

71. Wu YB, Qiu GR, Xu LB. Clinical observation on the treatment of 43 cases of atopic dermatitis with TCM syndrome differentiation and clarityne. JiangSu J Tradit Chin Med [Jiangsu Zhong Yi Yao]. 2014;46(6):49-50 (In Chinese).

72. Li WZ. Observation on therapeutic effect of a traditional Chinese medicine empirical formula on atopic dermatitis. Chin Commun Dr [Zhongguo Shqu Yi Shi]. 2006;8(14):118-9 (In Chinese).

73. Li XJ. Effect of Chinese medicine in treatment of atopic dermatitis. China Health Stand Manag [Zhongguo Wei Sheng Biao Zhun Guan Li]. 2015;6(19):139-40 (In Chinese).

74. Zhang J. Clinical research of traditional Chinese medicine in the treatment of atopic dermatitis. China J Chin Med [Zhong Yi Xue Bao]. 2012;27(7):897-8 (In Chinese).

75. Zhou $L$. The clinical observation of treatment of atopic dermatitis using granules of Ziyin Jianpi decoction. Master thesis. Hubei University of Chinese Medicine; 2012. (In Chinese).

76. Gu SX, Zhang AL, Coyle ME, Mo X, Lenon GB, Cranswick NE, et al. Chinese herbal medicine granules (PTQX) for children with moderate to severe atopic eczema: study protocol for a randomised controlled trial. Trials. 2015;16:1-6.

77. Cheng HM, Chiang LC, Jan YM, Li TC, Chen GW. The efficacy and safety of a Chinese herbal product (Xiao-Feng-San) for the treatment of refractory atopic dermatitis: a randomised, double-blind, placebo-controlled trial. Eur J Integr Med. 2012;4(SUPPL. 1):69.

78. Cuellar MJ, Giner RM, Recio MC, Just MJ, Mañez S, Rios JL. Effect of the basidiomycete Poria cocos on experimental dermatitis and other inflammatory conditions. Chem Pharm Bull. 1997;45(3):492-4.

79. Kaminaga T, Yasukawa K, Kanno H, Tai T, Nunoura Y, Takido M. Inhibitory effects of lanostane-type triterpene acids, the components of Poria cocos, on tumor promotion by 12-O-tetradecanoylphorbol-13-acetate in twostage carcinogenesis in mouse skin. Oncology. 1996;53(5):382-5.

80. Prieto JM, Recio MC, Giner RM, Máñez S, Giner-Larza EM, Ríos JL. Influence of traditional Chinese anti-inflammatory medicinal plants on leukocyte and platelet functions. J Pharm Pharmacol. 2003;55(9):1275-82.

81. Koonrungsesomboon N, Na-Bangchang K, Karbwang J. Therapeutic potential and pharmacological activities of Atractylodes lancea (Thunb.) DC. Asian Pac J Trop Med. 2014;7(6):421-8.

82. Wang XR, Zhou C, Zhong ZD, Duan Q, Du AY, Jing G. Effect of modified Danggui Yinzi on delayed allergy in model mice with Qi-blood deficiency syndrome. Zhongguo Zhong Xi Yi Jie He Za Zhi. 2016;36(3):345-7 (In Chinese).

83. Yan F, Li F, Liu J, et al. The formulae and biologically active ingredients of Chinese herbal medicines for the treatment of atopic dermatitis. Biomed Pharmacother. 2020;127:110142.

84. Man MQ, Hu LZ, Elias PM. Herbal medicines prevent the development of atopic dermatitis by multiple mechanisms. Chin J Integr Med. 2019;25(2):151-60

85. Kim J, Kim H. Combination treatment with herbal medicines and western medicines in atopic dermatitis: benefits and considerations. Chin J Integr Med. 2016;22(5):323-7.

86. Zhang CS, Yu JJ, Parker S, Zhang AL, May B, Lu C, et al. Oral Chinese herbal medicine combined with pharmacotherapy for psoriasis vulgaris: a systematic review. Int J Dermatol. 2014;53(11):1305-18.

\section{Publisher's Note}

Springer Nature remains neutral with regard to jurisdictional claims in published maps and institutional affiliations.
Ready to submit your research? Choose BMC and benefit from:

- fast, convenient online submission

- thorough peer review by experienced researchers in your field

- rapid publication on acceptance

- support for research data, including large and complex data types

- gold Open Access which fosters wider collaboration and increased citations

- maximum visibility for your research: over 100M website views per year

At BMC, research is always in progress.

Learn more biomedcentral.com/submissions 